\title{
A Strategic Response Through Distance Learning: A Case of The Arab Open University.
}

Abdulkarim Al-Nahas, (E-mail: alhemoud@arabou.org), Arab Open University, Kuwait Abdulla Alhemoud, Arab Open University, Kuwait Fahad Al-Mekrad, Arab Open University, Kuwait

\begin{abstract}
The Arab countries of the Middle East and North Africa face the challenge of providing educational opportunities to various sections of society to be able to meet the needs of the changing labor markets. Indeed, incessant efforts have been made by the governments of these countries to develop the education sector rapidly. However, they still have a long way to go before the avowed objective of spreading education far and wide in these countries is met. This paper makes an attempt to examine and analyze a strategic response in the form of distance learning to the changing labor market needs in the Arab world with special reference to the establishment of the AOU, Kuwait Branch. The paper suggests a suitable strategy for ensuring cooperation between labor markets and education sector in the Arab world.
\end{abstract}

\section{Introduction}

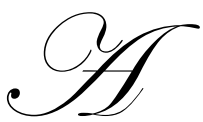

vailable evidence explicitly suggests that countries of the Middle East and North Africa, including the Arab nations spend, on average nearly 6 percent of GDP on education (Abed, 2003) .However, some of the threads running through the education sectors of these countries are discouraging. For instance, the education system has not been successful in attaining the desired heights of efficiency and the governments have to subsidize higher education and vocational training programs. Moreover, the system is ineffective in so many countries due to high dropout and repetition rates that neutralize, to a great extent, evidence of high enrollment. Curiously enough, the enrollment trend in so many countries, most notably in Egypt and Morocco, demonstrates inequity in terms of demographic and geographic factors (Abed, ibid; UNDP 2002; World Bank 1999).

With a view to making the education sector fruitful and effective in interaction with the changing labor market conditions in the Arab world, it has been argued with emphasis that to reduce the risk of unemployment and a mismatch between skills and job market opportunities, there must be deregulation of labor markets and the private sector should be encouraged to play its role in creating educational opportunities. Policy interventions that target the poor and the vulnerable sections of society are likely to pay rich dividends in the Arab countries (Abed, op cit)

Against the backdrop of this argument in contemporary literature and the need to respond effectively to the changing needs of the labor market, we now turn to examine and analyze a unique initiative to create distance education opportunities for a cross-section of people in the Arab world. The initiative has paved the way for the establishment of the Arab Open University (AOU) in Kuwait and its branches in Saudi Arabia, Lebanon, Jordan, Bahrain, and Egypt. It is indeed a unique private sector initiative with support from the governments to provide educational opportunities to various sections of the Arab society across countries. It is anchored in sound theory as explained in the following section. 


\section{Historical and Theoretical Perspectives}

Recent years have witnessed fantastic growth in the area of distance education. Available evidence indicates that in 1993, there were 1.3 million students enrolled in distance education (Banas and Emroy, 1998). The number topped 11 million in 1999 (Hankin, 1999). It is likely to multiply in the current decade.

The latest innovations in computers and the Internet provide additional new technological advances challenging the traditional classroom teaching method (Bates, 1991; Burdman, 1998). Australia, Canada, and European countries have taken steps to move toward distance education to provide more access to education for their population. The Open University, UK, for example, was established in 1971 to facilitate greater access to higher education for adults. In the 1997/98 school year, it represented $21 \%$ of the part-time students throughout Britain. For Australia and Canada with a large land mass and a relatively small and scattered population, it has been imperative to use distance education to reach out to as many learners as possible.

Conventional wisdom suggests that a desirable goal that distance education promises is that in offering education to the masses it can effect educational and social change. Unfortunately, according to some studies, this does not seem to have happened at the beginning. Students' perceptions of overall interaction in a distance learning class were not necessarily related to individual participation (Fulford \& Zhang, 1993). Interestingly, learner-learner exchanges were becoming equally if not more important than learner-instructor interaction in online environments (Ritchie \& Newby, 1989; Wegegrif, 1998). The importance of distance learning interactions has been noted (Hayes, 1990; Hilts \& Wellman, 1997; Wegegrif, 1998) and most researches examining web-enhanced environments focus on strategies increasing instructor-student interaction and individual participation (Fulford \& Zhang, 1993).

A crucial aspect of distance education's promise is that it is cost effective. It promises a quality-oriented and relevant education for the masses which can bring about educational and social change at lesser cost than conventional education. However, in reality, distance learning may not be cost effective compared with traditional learning (Navarro, 1998).

The economic development of the Arab world and its integration in the world economy require universities to prepare able professionals and managers to be effective in a competitive environment. The idea of establishing an Arab Open University (AOU) was floated in 1976. Attempts to address the urgent need for AOU have been revamped when HRH Prince Talal Bin Abdulaziz took the initiative in September 1996. Numerous studies have been completed which supported the educational, cultural and social feasibility of AOU. A meeting of the Arab Gulf Program for United Nations Development Organizations (AGFUND) was held in Riyadh, Saudi Arabia under the patronage of $\mathrm{HRH}$ in October 1997. The meeting resolved the following:

1. Establishing AOU is an urgent necessity dictated by the changes and developments in the Arab world.

2. The basic infrastructure for AOU is available in many Arab countries to support the university.

3. The project is educationally, culturally and socially feasible and will support national development in the Arab world.

4. $\quad$ Trained and competent human resources are available in the Arab world.

5. AOU is supported by the international and Arab organizations.

6. AOU will meet the needs of the Arab nations and lead to the improvement of quality education.

Currently, younger population under the age of 20 in the Arab world is 10 percent greater than the rest of the world (Arthur Anderson, 1998). This poses a great challenge for the Arab world to provide quality education and training to ensure employment.

\section{Market Research}

A market research exercise was conducted in association with Arthur Anderson in 1998 for assessing the need of this kind of program in Kuwait and other Arab countries. The results showed that there are great needs for higher education in business studies. The report indicates that "unless there is a drastic increase in the capacity of 
traditional universities, the unaccepted students will increase substantially (page 10). Table 1 illustrates the extent of the current demand in the countries under review.

Table 1. Capacity and Potential Demand

\begin{tabular}{|cccc|}
\hline & Seat Capacity for $\mathbf{1}^{\text {st }}$ Degree ( 1997) & High School graduates (1998) & Potential Demand (1998) \\
Total & 600,765 & $1,228,945$ & 628,183 \\
\hline
\end{tabular}

Source: Arthur Anderson, Arab Higher Education Market Analysis

Table 2.

According to this report, the projected number of registered students in the AOU is expected to be as follow in

Table 2. Projected Number of Registered Students

\begin{tabular}{|llllll|}
\hline First year & Second year & Third year & Fourth year & Ninth year & Tenth year \\
5000 & 20000 & 40000 & 60000 & 140000 & 150000 \\
Growth & $300 \%$ & $100 \%$ & $50 \%$ & $17 \%$ & $7 \%$ \\
\hline
\end{tabular}

There are additional substantial needs in the Arab world for women's education and for continuing education. Approval was granted by the various ministries in the Arab world to open this university in the following Arab countries: Kuwait, Egypt, Bahrain, Lebanon, Saudi Arabia and Jordan.

Agreements with Arab countries hosting the initial set of branches have been officially signed by HRH Prince Talal, the President of AOU thereby granting the AOU an official status for operating as an institution of higher learning. Cooperation is taking place with universities in Lebanon, Jordan, Bahrain, Egypt, Saudi Arabia and Kuwait in addition to other Arab countries to utilize their qualified faculty members for part-time academic tasks for the benefit of the AOU.

\section{Program Development}

The Faculty of Business Studies is one of four faculties at the AOU. The university's other faculties include the Faculty of Education, The Faculty of Language Studies, and the Faculty of Computer Sciences. The AOU is a non-profit organization with the objective of helping tens of thousands of students of limited financial position to gain access to knowledge and education. Undergraduate and graduate programs of studies will help achieve this objective.

The AOU aims to spread education in the Arab world. This provides an outstanding opportunity to Arab citizens, irrespective of age, gender, income, geographical location and employment, to get higher and continuous education. This will eventually help in the development of human resources in all fields needed by the job market, and facilitate effective diffusion of modern technology.

The philosophy of the AOU is to make available to students, who meet the minimum entry requirements, the freedom to select courses and programs of study they desire. This is in contrast to traditional universities where entry into programs is governed primarily by achievements in high school examinations. Since high-grade achievers normally secure an entry into a traditional university for the programs they require, it is those with low grades in examinations that are left either with the undesired programs or are not admitted at all to a university. The open learning format provides these students with an opportunity to enroll for a program of study and thus be part of a fruitful educational endeavor.

A labor market needs analysis and the survey results provided by Arthur \& Anderson ( 1998) has established the need to design four programs of study including Business Administration with two tracks of 
specialization ( Economics and Management Information System), Computer Science, English Language, and Education) at the AOU. Only the first three programs will be conducted in English language and will be supported by the Open University, UK.

During the first year 2002/2003 the AOU established the following Bachelor's programs.

1. B.A. in English Studies

2. $\quad$ B.A. in Business Studies (Economics).

3. B.A. in Business Studies (Management Information Systems).

4. B.A. in Computer Science

The university will increase the number of programs offered in the following years for the B.A. degree programs and other higher degrees programs in order to cope with the demands and cater to the needs in the region. For the business program, the following two options were developed:

\section{Admissions and Registration}

In order to evaluate any process performance, one must be familiar with the inputs, actions, decisions, and outputs that comprise that process. The AOU is committed to recruiting students who have a high potential to successfully complete the requirements of its programs. The following rules and criteria constitute the university's basic policy on admissions.

* Students applying for admission should be holders of the "General Secondary School Certificate", or the equivalent thereof, without prejudice to year of achievement. The admissions application shall be made for a specific program of study. Admitted students should satisfy any other conditions set by the Board of Trustees, including special admission examinations. Admitted students may apply for the transfer of credits earned at other recognized higher education institutions, and may be granted some transfer credit hours. However, in all cases, a student must complete successfully the study of at least 64 credit hours of the total requirements of a program of study; generally set at a minimum of 127 credit hours.

* Upon admission the student sits for "Language Placement Tests". These tests are held in Arabic and English languages. Failing to pass the placement examination of a language makes it a requirement that the student registers for the first-level course of that language. Passing the test results in a credit for the first language course. All applicants are treated equally in terms of educational opportunities regardless of gender, age, color, national origin, socio-economic background, disability, religious or political beliefs. The board sets the numbers of students to be admitted annually; the numbers admitted to each program depend on available human and logistic resources. This is made so in order to safeguard the provision of quality learning. Admitted students, upon further academic advising, will be asked to register in the courses of the program to which they are admitted. For the first year, in particular, admissions and registration dates and procedures are announced to students in the local media, based on appropriate dates of the university calendar.

During the agreement reached with the Open University, UK the first term acceptance was set at 600 students for the Kuwait branch distributed among four programs. An increase was later decided reaching 1,500 students based on the high demand of students in Kuwait. The registration process first began on June, 2002 in Kuwait during morning and afternoon times and continued until July 2002. Tables 3 and 4 show the breakdown of first year applicants at the Kuwait branch. The majority of applicants (47\%) selected the business program. Descriptive analysis of applicants and accepted students for the first- term enrollment at the AOU is presented on tables 3 and 4 . 
Table 3. AOU, Kuwait Branch: First Term Applicants

\begin{tabular}{|c|c|c|c|c|c|c|c|}
\hline \multirow{2}{*}{ Program } & \multirow[t]{2}{*}{$\mathbf{M}$} & \multirow[t]{2}{*}{$\mathbf{F}$} & \multicolumn{2}{|c|}{ Kuwaiti } & \multicolumn{2}{|c|}{ Non-Kuwaiti } & \multirow[t]{2}{*}{ Total } \\
\hline & & & $\mathbf{M}$ & $\mathbf{F}$ & & $\mathbf{F}$ & \\
\hline \multirow{2}{*}{$\begin{array}{l}\text { B.A. in } \\
\text { Business/ } \\
\text { Economics }\end{array}$} & 485 & 240 & 302 & 112 & 183 & 128 & 725 \\
\hline & $8 \%$ & $4 \%$ & $5 \%$ & $2 \%$ & $3 \%$ & $2.1 \%$ & $(12 \%)$ \\
\hline \multirow{2}{*}{$\begin{array}{l}\text { B.A. in } \\
\text { Business/ } \\
\text { Systems }\end{array}$} & 1,330 & 781 & 967 & 403 & 363 & 378 & 2,111 \\
\hline & $22 \%$ & $13 \%$ & $15.9 \%$ & $6.6 \%$ & $6 \%$ & $6.2 \%$ & $(35 \%)$ \\
\hline \multirow{2}{*}{$\begin{array}{l}\text { B.A. in } \\
\text { English }\end{array}$} & 281 & 645 & 155 & 226 & 126 & 419 & 926 \\
\hline & $5 \%$ & $10.6 \%$ & $2.5 \%$ & $3.7 \%$ & $2 \%$ & $6.9 \%$ & $(15 \%)$ \\
\hline \multirow{2}{*}{$\begin{array}{l}\text { B.A. in IT/ } \\
\text { Computer }\end{array}$} & 1,430 & 872 & 713 & 359 & 717 & 513 & 2,302 \\
\hline & $23.5 \%$ & $14.4 \%$ & $11.7 \%$ & $06 \%$ & $11.8 \%$ & $8.5 \%$ & $(38 \%)$ \\
\hline \multirow{2}{*}{ TOTAL } & 3,526 & 2,538 & 2,137 & 1,100 & 1,389 & 1,438 & $\underline{6,064}$ \\
\hline & $58.1 \%$ & $41.9 \%$ & $35.2 \%$ & $18.1 \%$ & $22.9 \%$ & $23.7 \%$ & $(100 \%)$ \\
\hline
\end{tabular}

Table 4. AOU, Kuwait Branch: First Term Applicants By Programme of Study

\begin{tabular}{|l|c|c|c|c|c|}
\hline Certificate/Degree & \multicolumn{2}{|c|}{ Kuwaiti } & \multicolumn{2}{c|}{ Non-Kuwaiti } & \multirow{2}{*}{ Total } \\
\hline $\begin{array}{l}\text { High School } \\
\text { (English/U.S) }\end{array}$ & 26 & 16 & 07 & 06 & 55 \\
& $0.4 \%$ & $0.2 \%$ & $0.1 \%$ & 0.1 & $(0.9 \%)$ \\
\hline $\begin{array}{l}\text { Public H.S. } \\
\text { (Scientific) }\end{array}$ & 580 & 229 & 877 & 693 & 2,379 \\
\hline $\begin{array}{l}\text { Public H.S. } \\
\text { (Arts/Literature) }\end{array}$ & $9.6 \%$ & $3.8 \%$ & $14.4 \%$ & $11.4 \%$ & $(39.2 \%)$ \\
\hline $\begin{array}{l}\text { Public H.S. } \\
\text { (Semester/Credit }\end{array}$ & $71.9 \%$ & $5.6 \%$ & $6.6 \%$ & $9.9 \%$ & $(34.1 \%)$ \\
\hline System) & $11.7 \%$ & $8 \%$ & $1.2 \%$ & $1.9 \%$ & $(22.9 \%)$ \\
\hline $\begin{array}{l}\text { Other H.S. } \\
\text { TOTAL }\end{array}$ & 98 & 24 & 34 & 19 & 175 \\
\hline & 2,137 & 1,100 & 1,389 & 1,438 & 6,064 \\
\hline
\end{tabular}




\section{Acceptance Procedure}

Since AOU's Kuwait branch began its operations with limited resources, it could not handle all these applicants in its first enrollment. It was first decided to take around 1500 students during the first semester and the remainder of applicants in the following semesters in the hope that in the coming years, the university could accommodate up to 10,000 applicants at once.

The selection of accepted students from the 6064 total applicants was done by the Registrations and Records Department by taking various factors such as age, gender, and high school GPA scores/percentages into consideration. Preference was given to selected applicants with the highest high school grades. Priority was given to older students in the admission process. Female applicants were also given priority. The split in admission was as follows: $60 \%$ female students and $40 \%$ males. A minimum increase was later decided to bring the total acceptance for the first term to around 2000 students.

In the following years when all the resources are available within the university, selection criteria will be waived with the exception of a "General Secondary School Certificate" for all applicants.

The selected students are given in table 5. The majority of students (42.7\%) are enrolled in the business program of the university.

Table 5. AOU, Kuwait Branch: Student Numbers in First Term Registered by Program

\begin{tabular}{|c|c|c|c|c|c|c|c|}
\hline \multirow{3}{*}{$\begin{array}{l}\text { Program } \\
\text { B.A. in } \\
\text { Economics }\end{array}$} & \multirow{3}{*}{$\begin{array}{l}\text { M } \\
123\end{array}$} & \multirow[t]{2}{*}{$\mathbf{F}$} & \multicolumn{2}{|c|}{ Kuwaiti } & \multicolumn{2}{|c|}{ Non-Kuwaiti } & \multirow{3}{*}{$\begin{array}{r}\text { Total } \\
320\end{array}$} \\
\hline & & & \multirow{2}{*}{$\frac{\mathbf{M}}{56}$} & $\mathbf{F}$ & \multicolumn{2}{|l|}{ M } & \\
\hline & & 197 & & 95 & 65 & 104 & \\
\hline & $08 \%$ & $12.8 \%$ & $3.7 \%$ & $06 \%$ & $04 \%$ & $06.7 \%$ & $(21 \%)$ \\
\hline B.A. in & 136 & 195 & 71 & 86 & 65 & 108 & 331 \\
\hline & $09 \%$ & $12.7 \%$ & $4.6 \%$ & $5.6 \%$ & $4.3 \%$ & $07 \%$ & $(21.7 \%)$ \\
\hline & $\overline{99}$ & 187 & 53 & 83 & 47 & 103 & 286 \\
\hline $\begin{array}{l}\text { B.A. in } \\
\text { English }\end{array}$ & $6.5 \%$ & $12.2 \%$ & $3.5 \%$ & $5.5 \%$ & $3.1 \%$ & $06.7 \%$ & $(18.8 \%)$ \\
\hline & 240 & 347 & 111 & 153 & 127 & 196 & 587 \\
\hline Computer & $15.7 \%$ & $22.8 \%$ & $7.2 \%$ & $10 \%$ & $8.3 \%$ & $12.8 \%$ & $(38.5 \%)$ \\
\hline TOTAL & 598 & 926 & 291 & 417 & 305 & 511 & 1,524 \\
\hline & $39.2 \%$ & $60.7 \%$ & $19.1 \%$ & $27.3 \%$ & $20 \%$ & $33.5 \%$ & $(100 \%)$ \\
\hline
\end{tabular}




\section{Diagram 1: A Stylized Model of Distance Education Strategy in Interaction with Labor Market Needs}

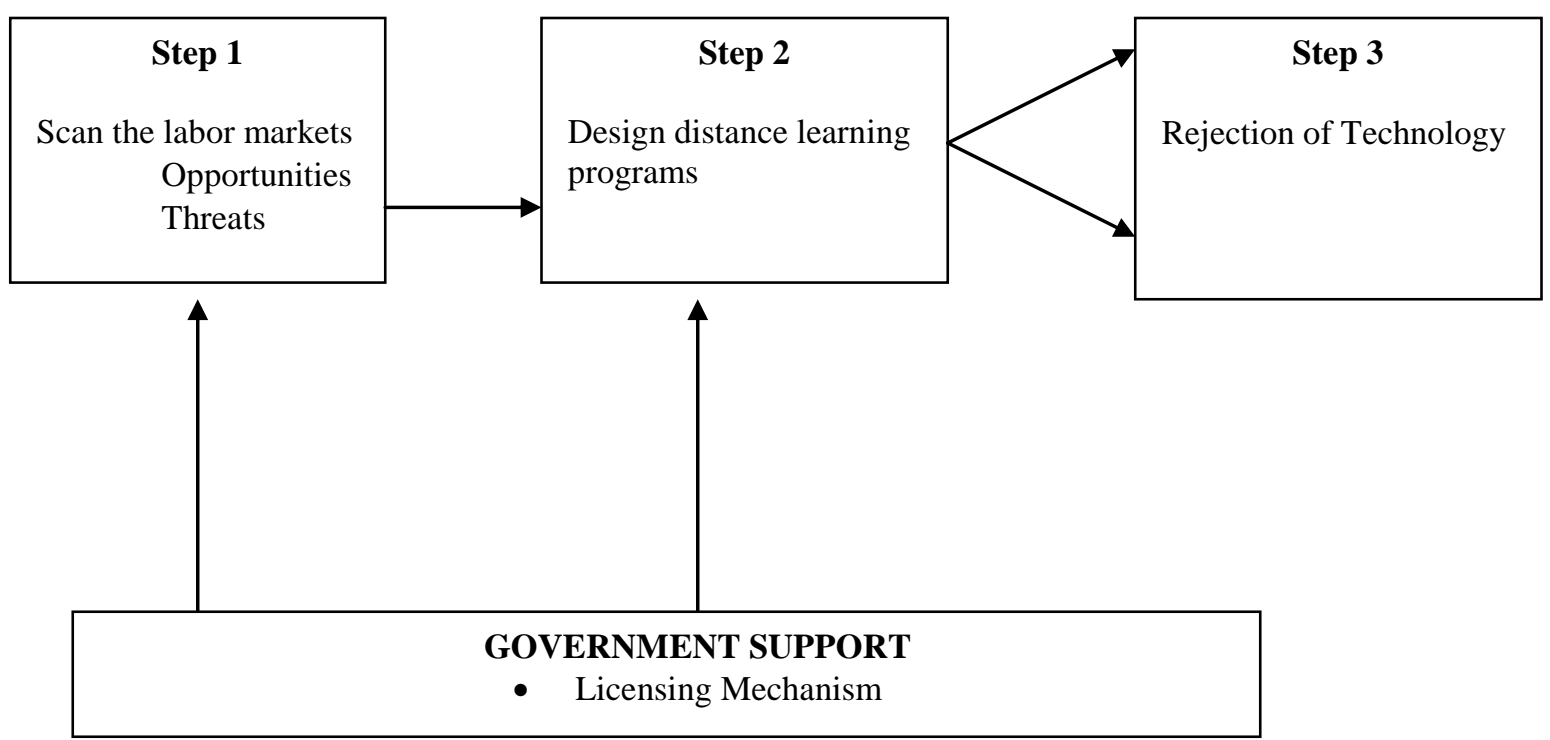

\section{Conclusions and Policy Implications}

The Arab countries have responded to the question of rapidly spreading education in the region by deciding to establish an open learning institution. The response to this initiative from the communities has been overwhelmingly positive as the increasing number of students in various programs suggests. Like many universities around the world, the AOU is undergoing significant changes in teaching methods as a result of the introduction of new technologies, particularly the World Wide Web, CD-ROMs and videoconferencing. It is clear that such developments are having a major impact on faculty, university managers, and government decision makers. International online teaching is also not an enterprise that should be undertaken lightly if a high quality and successful program is to be launched. It needs thoughtful market research, strong institutional support, and adaptability to local needs. Major administrative and bureaucratic obstacles will need to be overcome. Surely, it needs a dedicated and hardworking team with very strong motivation to succeed.

The creation of distance learning networks in the Arab world is certainly likely to interact favorably with changing labor markets in the world. Policy interventions that create employment opportunities for the poor and reduce vulnerability of the people in labor markets must have priority over conventional interventions that have proved costly and inefficient. Of course, there must be effective coordination of policies addressed to the needs of the labor markets in the Arab world. A stylized model of a strategic response to the changing needs of the labor market is presented in diagram 1 .

It is clear from the diagram that labor markets must be scanned neatly before designing any kind of response. The case in point is distance education. Without doubt, no distance learning program can succeed if there is a mismatch between the program and needs of the market. In other words, all the distance learning programs must be market-oriented. Step 3 in the model suggests that outdated and irrelevant technologies must be rejected and new technologies to organize and deliver distance education must be accepted. Surely, in the final analysis, it is the dissemination of knowledge that matters. The students and faculty must be mentored and trained on a continuous basis to make the distance learning programs a success. Distance education must be anchored in the reform programs undertaken by Arab countries to accelerate the pace of socio-economic development. 


\section{References}

1. Abed, George, T., 2003. Unfulfilled Promise: Why the Middle East and North Africa Region has Lagged in Growth and Globalization, Finance and Development, IMF/World Bank, Washington, D.C. ( March), pp 10-17.

2. Arthur Anderson \& Co. 1998. Arab Open University Feasibility Study Draft Report. Unpublished Technical Report.

3. Banas, Edward J. and Emroy, F. W. 1998. History and Issues of Distance Learning, Public Administration Quarterly, 22, pp 365-83.

4. Bates, W.W. 1991. Third Generation Distance Education: The Challenge of New Technology, Research Distance Education, 3(2), pp 10-16.

5. Burdman, P. 1998. Cyber U. Orange Register Connect, pp. 1-9, (13 September).

6. Hankin, Joseph, N. 1999. Alice, the College Teacher, and the Rottweiler in Wonderland: The Problems and Prospects of Distance Education, Executive Speeches, 14 (2), pp 18-21.

7. Hayes, E. 1990. Adult Education: Context and Challenge for Distance Educators. American Journal for Distance Education, 4(1) pp25-38.

8. Hiltz, S.R., \& Wellman, B. 1997. Asynchronous Learning Networks as a Virtual Classroom. Communications of the ACM, 40(9), pp 44-50.

9. Fulford, C.P., \& Zhang, S. 1993. Perceptions of Interaction: The Critical Predictor in Distance Education. American Journal of Distance Education, 7(3), pp8-21.

10. Ives, B., \& Jarvenpaa, S.L. 1996. Will the Internet Revolutionize Business Education and Research? Sloan Management Review, Spring, pp33-41.

11. Navarro, P. 1998. Notes from the Electronic Classroom. Journal of Policy Analysis and Management, 17(1), pp106-115.

12. Ritchie, H., \& Newby, T.J. 1989. Classroom Lecture/Discussion versus Live Televised Instruction: A Comparison of Effects on Student Performance, Attitude, and Interaction. American Journal of Distance Education, 3(3), pp 36-45.

13. UNDP, 2002. The Arab Human Development Report, New York.

14. Wegegrif, R. 1998. The Social Dimension of Asynchronous Learning Networks. JALN, 2(1): pp1-17.

15. World Bank, 1999. Education in the Middle East and North Africa: A Strategy Towards Learning for Development, Middle East and North Africa Region, Human Development Department, Washington, D.C. 